\title{
Agile Workplace Innovation
}

\section{Thomas Papke and Dirk Nicolas Wagner}

\begin{abstract}
Agile methods, such as Scrum, first re-invented project management in software engineering. It then quickly spread into all kinds of areas and industries. Scrum is " a framework within which people can address complex adaptive problems" (Schwaber and Sutherland 2013), and it changes the way work is done. It can be shown that Scrum is a suitable method to support Workplace Innovation. The concept of Workplace Innovation, described here with the 'Fifth Element Concept' (Totterdill 2015), comprises practices that empower and enable employees and that are beneficial for organisations. To obtain an understanding of how Scrum supports Workplace Innovation, guided interviews were conducted and analysed. Five practitioners of Scrum were interviewed, and the analysis was carried out using Mayring's qualitative content analysis with an inductive coding. This article aims to gain insights into how and where Scrum can support Workplace Innovation, and what other factors have a significant influence. Scrum may not be a silver bullet, but it can be instrumental in supporting many elements of Workplace Innovation.
\end{abstract}

Keywords: Agile Management, Scrum, The Fifth Element, Workplace Innovation 


\section{Introduction}

\section{The challenge to achieve Workplace Innovation}

Examples for Workplace Innovation are practices which give employees the power of decision in their day-to-day activity, enable them to contribute ideas, question established ways of business and allow them the opportunity to be heard at the top management level. Nowadays there is more and more evidence showing that Workplace Innovation contributes towards better results for businesses while also enhancing health and engagement amongst the workforce (Totterdill 2015, p.56).

Totterdill (2015, p.57) ascribes great importance to the concept of Workplace Innovation as a constant social process. Workplace Innovation defines the contributive process of innovation that flows into outcomes in the shape of participatory workplace practices. Participatory methods, based on reflection, learning and improvement, support the process of innovation in managing, organising work and applying technologies.

Ennals (2014, p.112) highlights, that Workplace Innovation cannot be treated as an isolated object, but should incorporate experiences from various contexts in working life. Totterdill (2015, p.56) proposes a framework, the 'Fifth Element Concept', which should help to understand, stimulate and enable high-performing workplaces through empowering employees and fostering their engagement.

According to Ennals (2014, p.112), this framework is vital and effective for organisations and considers state of the art research. Gkiontsi and Karanika-Murray (2016) provide an example of how the framework can be applied systematically in the specific context of demographic change. The framework was initially designed to allow employers and employees and other stakeholders in policy making, research, social partnership or consulting to be involved in shaping a vision of a high performance and high quality of working life organisation by contributing their knowledge and experience. As it is a complex concept, an emphasis was put on making it more communicable, bearing in mind the extensive underlying research (Totterdill 2015, p.62).

The first element of the framework is work organisation. Employees taking the initiative and being able to work without supervision are valued, as it enables the workforce to make decisions based on their practical experience and to avoid delays that happen during coordination with management. Employees often know best what their customers want and their co-workers need. Job design is the starting point in building a workplace that enables the workforce to deploy its skills, develop him or herself and get creative. Good job design should be integrated into an organisation's context. The core concept to achieve this is teamwork. Teamwork has a long tradition in European management thinking, and is one of the key concepts in the new organisation of workplaces. Teams that enjoy empowerment and self-organise are one of the key factors in workplace innovation (Totterdill 2015, p.65).

The second element is structures and systems, which deals with reducing organisational walls and ceilings, supporting initiative amongst employees, ensuring fairness and equality and building trust. People should no longer be allocated to departments and divisions, but rather be able to interact with others in their organisation to understand their tasks, problems and skills. To become an innovative workplace, it is necessary to embed the idea of empowerment in all 
systems, and into all policies of an organisation. Good coaching for high performance, when managers act as team leaders, leads to continuous improvement. Managers should see it as a way to enhance the performance of a whole team, which can be achieved through sharing best practices and discussing problems on a team level in an open and target-orientated environment (Totterdill 2015, p.66-67).

The third building block is learning, reflection and innovation (Totterdill 2015, p.67). Pot states that managerial and organisational innovation seems to be more important than technological innovation (Pot 2011, p.406). Consistently generating ideas to improve the business should be incorporated into the daily work. Continuously getting new ideas for products, services or improved process is important for organisations. This can happen during dedicated times, in certain places or during everyday business if it enables dialogue and creativity amongst the workforce (Totterdill 2015, p.68). Tidd and Bessant (2013, p.130-131) state that this kind of innovation, as shown above, known as high involvement innovation, needs to be rooted deeply in an organisation. Employee engagement needs to be channelled from upper management to support empowerment and cleverness in daily work to ensure sustainability and effectiveness. Ramstad also argues that high involvement innovation practices, such as decentralised decision making and cooperation, can lead to valuable results for organisations and the workforce (Ramstad 2014, p.25).

The fourth element is workplace partnership, which is about dialogue, representative presentation, an open and commutative work environment, being involved in change processes and the integration of tacit and strategic knowledge (Totterdill 2015, p.69). Cressey et. al. (2013, p. 240) state, that workplace partnership is moving away from its focus on industrial relations, and is changing into a possible driver of organisational innovation.

The integration of many aspects has synergetic effects, which Totterdill identified to be customer focus, employee engagement and enabling culture. Furthermore, he regards resilience, positive employee relations and enterprising behaviour as synergetic effects (Totterdill 2015, p.64). Totterdill (2015, p.70) highlights that an adequate amount of research demonstrates how none of the building blocks exists in isolation, but rather are under the influence of one another. His concept illustrates the significance of understanding the interdependence amongst the workplace practices that are specified here and he concludes that if all this comes together, the outcomes are "high performance, good work and sustainable organisations" (Totterdill 2015, p.64).

Kalmi et. al. (2008, p.437) highlight that previous research had different outcomes concerning the impact of Workplace Innovation. However, Pot and Koningsveld show that the benefits of developing workplaces are plenty, but also hint that doing so is difficult. To do so successfully, participatory schemes that include employees seem superior to top-down approaches (Pot and Koningsveld 2009, p.421). The conditions for success or failure in Workplace Innovation, in general, are elaborate. The most important condition for success appears to be the commitment of management, together with the participation of the workforce (Pot 2011, p.412). 


\subsection{How agile management methods may lead to Workplace Innovation}

Salesforce.com, a global software company, is an example of a company successfully using Scrum, after transforming itself from traditional management in just three months in 2007. Since then they achieved remarkable results. In the first year after the changes, Salesforce.com released $94 \%$ more features, output per developer rose by $38 \%$ and customer value by $500 \%$, compared to the year before. After the implementation, Salesforce.com asked its employees about their experience with Scrum. Before implementing Scrum, only $40 \%$ had a good time working there. Afterwards, $86 \%$ did and $92 \%$ of the workforce would advocate Scrum to others (Denning 2013, p.6). In this case, Scrum had a positive effect on many aspects of Workplace Innovation.

Agile methods are based on the idea of the agile manifesto from 2001, which values, "individuals and interactions over processes and tools, working software over comprehensive documentation, customer collaboration over contract negotiation and responding to change over following a plan" (Kent et. al 2001). For years, neither business schools nor senior managers paid much attention to agile management methods. Although it is widespread in software development, for more than a decade, not much research was undertaken on it as an innovative managerial practice (Denning 2013, p.7).

Scrum is the leading form of agile management (Denning 2013, p.6). It can be used in other sectors than software development to improve quality and collaboration radically. With Scrum, an automotive supplier reported improvements in team autonomy, decision power and collaboration. Scrum showed its power through its rituals, transparency and roles. Good coaching through a so-called "Scrum Master" improved work results and supported the transition phase towards agile management. Besides that, team building was done on the job, as teams got better quickly over time as they had quick wins each week (Brandes et. al 2014, p.162-164).

Today agile methods are used in various industries and business functions. They are utilised to develop machinery at John Deere, create National Public Radio's programme, shape marketing at the cloud company Itronis, or are applied in everything from production to human resource at companies such as logistics provider C.H. Robinson, Mission Bell Winery, or GE (Rigby et.al. 2016).

There is evidence that may lead to the conclusion that companies from most industries face comparable problems and challenges when it comes to innovation. Many companies already use agile approaches, even though more traditional industries seem less keen to implement agile methods. In general, agile methods can well be used in other sectors, possibly at least for innovation projects, or tasks that ask for more flexible management than before (Conforto et. al. 2014, p.27-31). Hence, in the future, agile management methods are likely to become more and more important for organisations outside software development (Randall 2014, p.26-29).

Moe et. al (2009, p.480-490) conducted a field study in a company that had implemented Scrum, hoping for improvements in their ability to deliver iteratively, improving quality and better teamwork. They found that teams are better off when they self-manage, and agile methods enabled them to do so. Trying to establish what teams think of agile approaches such as Scrum, Williams (2012, p.72-76) conducted two surveys, which showed significant support for the principles of the agile manifesto. 
Scrum has been associated with many positive (psychological) effects on the workforce, such as shared responsibility through dedicated roles, self-management of the workload, and motivation due to the feasibility of the increments. Furthermore, Scrum is designed to enable teams to openly talk about problems with their work and their work environment, and find a solution by adjusting the plan. Additionally, all information is shared, and help can be provided easily as all team members are informed about the progress. Under Scrum, problems and their solutions are perceived as emergent. Hence, this takes away the pressure to perform and fear of failure. The chance to regularly talk about one's work eases pressure and allows everyone to be heard (Goll and Hommel 2015, p.110-111).

It has been shown that Scrum can improve team productivity and employee satisfaction. With Scrum, the time spent on unnecessary meetings and documentation of processes can be reduced. In collaboration with customers, their engagement and satisfaction can be increased, as it leads to more transparency and adaptability to their needs during the process. Ideally, Scrum teams are interdisciplinary, which supports the organisational learning and builds trust and respect among coworkers. Moreover, the approach can have positive effects on senior management, as it frees up their time when they no longer squander their time on project management tasks. Hence, they can spend it on tasks of higher importance, such as prioritising strategic projects, increasing collaboration across departments and removing impediments (Rigby et.al. 2016).

\section{Tasks, Roles and Workflow within Scrum}

Scrum is rooted in Japanese thought and practice (Sutherland 2014, p.38). Nonaka and Takeuchi state in their much-regarded classic paper, that speed and flexibility are highly essential for new product development. As companies no longer get the results they seek, their analysis proposes a holistic approach for successful teams. It has six characteristics: "built-in instability, selforganising project teams, overlapping development phases, "multilearning," subtle control, and organisational transfer of learning (...) companies are using a holistic method--as in rugby, the ball gets passed within the team as it moves as a unit up the field" (Nonaka and Takeuchi 1986, p.137). The term Scrum refers to the above-described way "the team works together through careful alignment, unity of purpose and clarity of goal" (Sutherland 2014, p.8). Ken Schwaber and Jeff Sutherland defined Scrum, in their "Scrum Guide", as "a framework within which people can address complex adaptive problems, while productively and creatively delivering products of the highest possible value" (Schwaber and Sutherland 2013).

The Scrum team consists of three roles, the Product Owner, the Scrum Master and the development team. Firstly, the Product Owner is responsible for what will be done and when in the development process. She has the authority to decide what will be done, communicates the vision of what the team is about to achieve and collaborates with the other roles. The Scrum Master is in charge to guide the team towards an adjusted process for the task based on the Scrum framework. She ensures understanding of the values, principles and practices of Scrum and embraces them. The Scrum Master as a facilitator supports the organisation in change processes, removes obstacles and provides expertise, leadership and protection from disturbing outside intervention. Even though her role is not the one of a project manager, it can be the one of a leader. Lastly, the development team decides independently how it will get done what is asked for. In general Scrum teams are cross-functional, diverse, no larger than five to nine 
members and should have all the skills they need for the task. Scrum teams are self-organising, thus they can decide best how to achieve their targets (Rubin 2012, p.14-16).

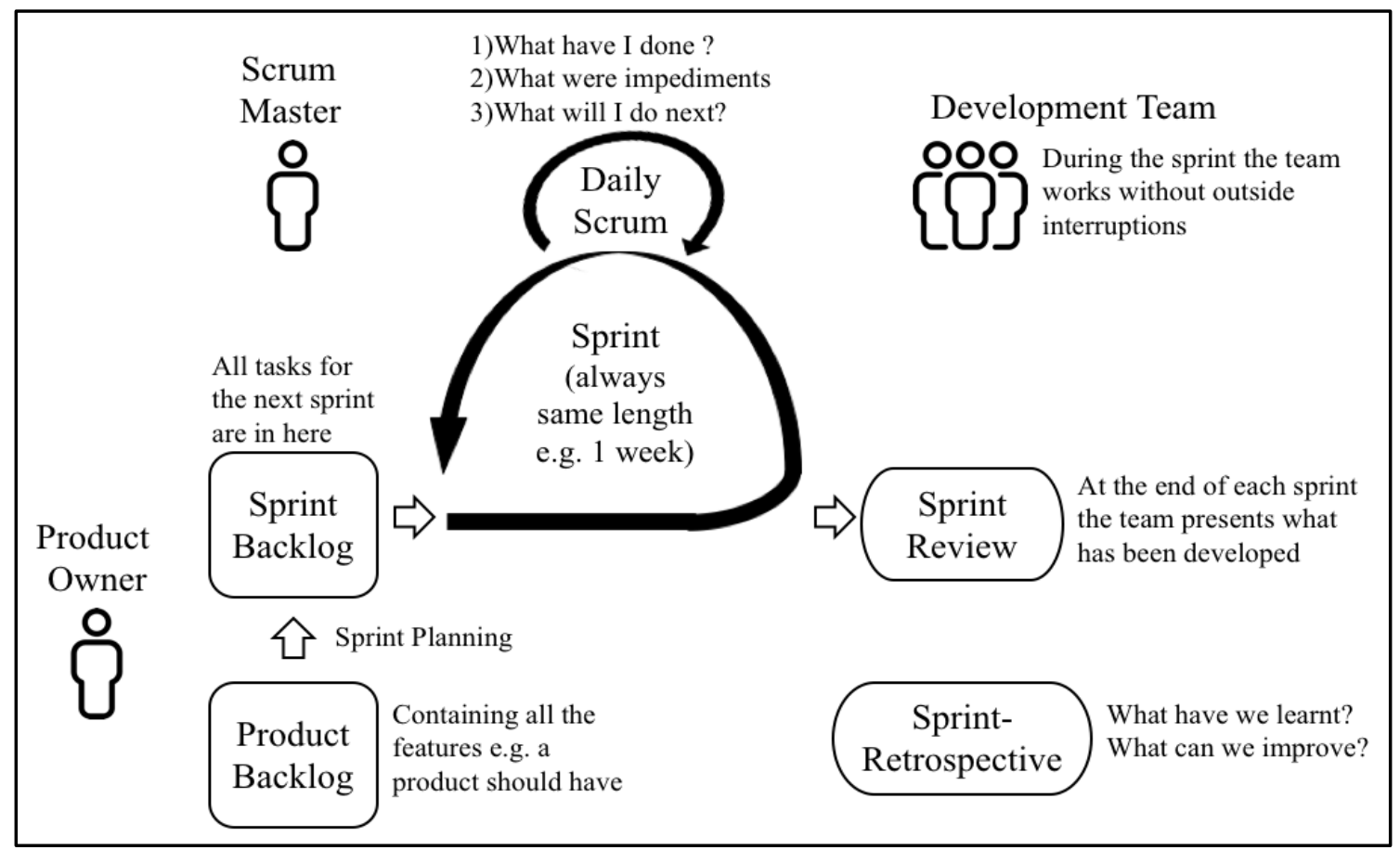

Figure 1: The Scrum Workcycle (adopted from it-agile.com (2015))

For the purpose of this study it is useful to briefly summarise how Scrum teams work: At the outset, the Product Owner writes all the requirements into a so-called Product Backlog (Rubin 2012, p.17-18). To build the Product Backlog, the Product Owner might make use of techniques such as Design Thinking or Crowdsourcing (Rigby et.al. 2016). Its content is prioritised by the estimated value the items provide to customers and stakeholders. As the Product Backlog (1) is too large to be completed in one go, the development team must decide on a portion of the tasks that they think they can complete in one Sprint. This is done as part of the beforehand Sprint planning (2). To get to work so-called Sprints (3), which are work cycles with the same length (for example two weeks), are held. To ensure that targets are met, the development team does not only forecast, but also commits to their goals. To support the development team during the Sprint, they create a Sprint Backlog (4) in which in further detail they break down their plan on how to complete features in one Sprint time. Next up, the Sprint is held, and the team gets to work. During the Sprint so called Daily Scrums (5) are held, where the team gets together to ensure the flow of their work by synchronising each other, doing a check-up on their work and adjusting their planning. As they complete one Sprint, they should have achieved one increment of their product. Now Scrum, which works in cycles, repeats, and starts with the next Sprint. Usually, after each Sprint, the team conducts a Sprint Review (6), where the stakeholders and the team examine what has been done. After one or more Sprints, the Scrum team itself does a Sprint Retrospective (7) where they review their Scrum process. They reflect on how they worked together and what they can change. (Rubin 2012, p.17-18). 
Negative effects of Scrum can be underestimating cross-sectional tasks, and only be thinking short term. Hesitating to make decisions may have adverse consequences because costs may rise over time (Goll and Hommel 2015, p.110-111). Morris (2013, p.91) further criticises that agile methodologies mainly focus on delivering an increment of work and hence run the risk of needing more resources than planned, exceeding budget, or not meeting schedule and scope requirements. Additionally, he emphasises the danger that focusing on short-term increments may lead to losing track of the overall progress in a project, which may hurt the overall value and realisation of benefits. However, he acknowledges the positive impact Scrum has had in software development.

\section{How SCRUM can support Workplace Innovation: Business practice perspectives}

\section{Overview of Research Process}

To explore how Scrum can support Workplace Innovation, based on primary data, guided interviews were undertaken. Interviews of an average length of 45 minutes were conducted with five practitioners of Scrum. The interviewees worked in various areas such as software development, project management services and consulting. All interviewees were made aware that the interviews would be recorded.

Qualitative methods were chosen over quantitative methods, as they enable more interaction and communication with the interviewee, more background on each of the topics, processorientation, consistency and authenticity, further in-depth questions that prevent misconception and an individual approach. Besides that, they can add valuable input and ideas from the interviewees. The output of qualitative evaluation is more case-related and richer in context (Kuckartz 2008, p.66-70).

The gathered data was analysed with the help of software, as the goal was to systematically analyse linguistic material (Mayring 2010, p.110). This approach seems best, if one plans to work inductively, previous knowledge is small, and exploration is the primary goal (Kuckartz 2010, p.92-96), which was the case for this work. A qualitative analysis may be of use and might feature enlightening insights even if, as in this case, it was based on a small number of interviewees (Brinkmann 2013, p.90). Mayring's qualitative content analysis can be used to generate hypotheses (Mayring 2010, p.22). In this case, the categories were developed in an inductive way, as the interviewees quoted other factors, which do not fit into the concept of Workplace Innovation. There is an apparent overlap in the inductive categories and parts of the 'Fifth Element for Workplace Innovation'.

This work cannot fully represent the complexity of the underlying concepts. The authors acknowledge that the reliability and ability to draw generalisations from this work are clearly limited and the conclusions are subject to the authors' subjectivity. 


\section{The use of Scrum}

Most interviewees used the whole Scrum framework in their organisations. Scrum had been introduced into the respective organisations on average more than four years ago. Mostly it had been tried in teams and then implemented following a bottom-up approach in other teams.

One interviewee stated that only parts of Scrum, such as the Daily Scrum, were used. This was done to improve communication among the team members. The quote from an interviewee: "What is definitely very helpful are the Daily Scrums, where one gets to know what the others are working on, where they struggle...can I maybe help them?" illustrates for example, how switching to daily meetings improved communication compared to longer weekly meetings that only led to frustration in the team. It was further said that "the people that before haven't talked to each other, suddenly work well together... and many topics are triggered from the team".

All interviewees agreed that Scrum is a very useful method in software development, but they were divided about the use of Scrum in other areas or projects with a big scope. The use of Scrum can also depend on the customer's requirements, and if results are needed quickly. In most cases, Scrum was still used in software development, but there were also efforts to embed Scrum or other agile methods into the whole organisation. Whether Scrum is utilised in other areas seems to depend on the industry, and the kind of project. One interviewee stated an example of Scrum used in hardware development, where he saw the same benefits as in other projects. One interviewee reported that he knew "...of examples from NGOS...or service departments such as HR or others, that switched to an agile approach". All interviewees agreed, even though Scrum might not be useful for all kinds of projects, they saw clear benefits in using Scrum and "would not like to go back to where our company came from, that usual project management business".

Scrum itself may only be a framework that will not solve any problems. But in the opinion of the interviewees, Scrum seemed superior to other methods. Nevertheless, there might be a danger to see Scrum as "a magic bullet that cures all problems that we see come up in projects".

Apparently, the implementation of Scrum often fails. When this happens, Scrum might become a neglected method, as its implementation failed due to various reasons. One interviewee stated that Scrum is often misunderstood "... as something for software developers. And not a crossorganisational management framework". To prevent a failure when implementing Scrum, good coaching seems vital. It was stated, that if teams see that Scrum has no benefits for them and their project, they stop using it.

As Scrum only provides a framework, it still is up to the teams to fill that, and make use of methods that fit into the framework. One interviewee said that „,...there are no precise approaches. And I see this sceptically, because one can do much good, one can also make many mistakes." Suitable methods could, for example, be tools to structure the retrospective meetings or communities of practice that enable knowledge sharing across teams.

Furthermore, it was stated, that the teams are often not homogenous and hence an equal distribution of tasks may be difficult which may have a harmful impact on team performance. Scrum may best be used when the teams are small and located in one place. If teams are not 
located in the same spatial area, Scrum was not the preferred method, as communication and Daily Scrum meetings are more complicated to organise.

Besides that, one interviewee stated, that self-management of teams is hard to do. To get to that state successfully, requires a manager, or in this case a Scrum Master, who is one of the most important factors when doing Scrum. Three of the interviewees were in the role of the Scrum Master. The all had different backgrounds and gained experience in various roles before becoming a Scrum Master. One interviewee described his role as a facilitator, where his task was to ensure that the Scrum process itself works smoothly and excellent products are produced.

All interviewees saw the power of Scrum in the short work cycles, which enabled better planning and predictability, as this statement shows: "The benefit of the method Scrum is, that usually one has a manageable timeframe and comparatively small tasks (...) that possibility of manageable iterative planning."

It was also emphasised, that currently, Scrum is a trending topic, “...which has led to a bit of hype around it. There is a danger that Scrum might quickly lose popularity and vanish from management's attention, just because sadly things are not done properly." What appears to be critical here is the fact that many managers put a lot of promises into it. But as Scrum is hard to do, and if the managers themselves do not see the necessity to change, the implementation of Scrum might fail. Currently, many organisations are experimenting with agile methods such as Scrum, but quite often these methods are not implemented correctly.

\section{Work Organisation}

The question how Scrum can contribute to Workplace Innovation was examined based on the experience of the interview partners. From the interviews, one can draw the conclusion, that Scrum supports job autonomy, if the team is composed of members that are willing to work autonomously. For some, it is an incentive to work more independently, but it can also lead to team members just drifting along and relying on others to plan and decide. Besides that, some team members may tend to cherry picking, which is counterproductive for the team result. Scrum, if done right, can be a method to empower employees.

One interviewee stated, that "the to do is already set, but the teams are free to decide on how to achieve it". However, the degree of freedom may vary. It may be the case that team members on their own identify tasks and problems, which according to the interviewees will not be the case in projects that are planned in a waterfall project management approach.

Regarding the aspect of self-managed teams, the impact of Scrum can be mostly positive but can also have negative implications, for example, if team members unlearned how to work on their own. What all interviewees agreed on is that the ability to self-manage is dependent on each team. They all quoted examples of teams, who quickly after having adopted the method Scrum, defined their own goals and were willing to do good work. But on the other hand, it can also be the case that teams do not develop themselves, or remain reluctant and are stuck in the expectation of being told what to do next, and how. This may be because they do not want to or they feel unable to do so. Apparently Scrum itself will not lead to self-managing teams but enables them. It is one of the Scrum Master's tasks to support the team in getting to that state. 
Scrum can also be a management system that allows the employee to achieve his or her goals in their way. The Scrum Master may also support the team by taking over "...many organisational matters...also for the individual responsibility of the team."

That teams can truly be self-managing is an illusion from the view of the interview partners, because some team members naturally take over more responsibility than others. But strong teams can self-regulate, if team members do not carry their weight. In an excellent way, the team divides its tasks considering the strengths and weaknesses of each team member.

Scrum may make employees more flexible in organising their own work, as they talk about their work in the Daily Scrum and "ideally the people divide the tasks independently amongst themselves." From one interviewee's perspective, Scrum, in general, can help to provide flexibility and to make use of it for every team member. But in some cases, employees can also misuse this flexibility.

Another aspect that was stated and can be related to the category of work organisation is improved planning. Planning drastically improved, as one could say much better what was available when. The iterative work style leads to results at the end of each Sprint, which can be as short as a week.

In conclusion, Scrum was identified to: in the experience of the interviewees, have had a positive impact on the aspect of work organisation, as described in "The Fifth Element concept." Whether Scrum supports Workplace Innovation or not appears to depend on how well Scrum is implemented and utilised.

\section{Structure and Systems}

The interviewees all reported that trust is vital for working together and that it is supported by Scrum. When the team with the help of the Scrum Master or a coach "... is being led there in the right way. (...) it works incredibly well, people who have not spoken to each other before, suddenly work well together and communicate openly with each other." Scrum appeared to build trust amongst team members even if they distrusted each other before. This may also happen if a natural hierarchy has already been established in the team. To build trust, management needs to let go, and the team members have to get to a point where they trust in the work of others. In teams, there are always different kinds of people who can deal with this better than others, but in general Scrum seems to support building and maintaining trust.

Scrum apparently also fostered employee initiative, and "for some is an incentive to work more independently". If used as prescribed, Scrum is a method to give more responsibility to teams and they often seem to appreciate this by showing more initiative. In the interviewees' experience, they observed more input, more suggestions and that "new tasks are recognised independently and proposed. You can not claim that in traditional project management, for example in the waterfall model." This might be due to the fact, that the team self-organised and had hence probably a better overview of the bigger picture. In some cases, this effect may also depend on the scope and topic of the project, but in general it seems to support employee initiative.

Scrum may enable teams to be fair and treat each other as equals. It is not clear whether this is 
only a result of Scrum or has already been, at least partially, the case. In general, it seems to have depended on the team and its team spirit. It does not inevitably lead to equality, but it "...enables a higher transparency. (...) the cherry-picking ones are easily spotted in such an environment". Teams differed in their reaction to such behaviour. Some teams exposed the weakest team member, while other teams tried to involve her or him better, to be able to achieve their goals on time together. What Scrum probably can provide, is that team members feel well incorporated and not left out.

Scrum may not be clearly attributed to reducing organisational walls and ceilings. In most of the interviewees' organisations, organisational barriers were already low. This might also be a prerequisite for the implementation of Scrum. But what can be said, is that in Scrum teams there are no fixed roles or hierarchy positions. Interestingly two interviewees stated:" ... that the physical walls in the office's spaces are no longer existent" as well. Most of the Scrum teams were seated in an open-office space to enable collaboration and improve personal communication.

\section{Reflection and Innovation}

Scrum seems to support the continuous improvement process of outcomes and processes. What needs to be in place to do so is that changes are noticeable for all team members. It is essential that issues that are under discussion are solved quickly and accordingly actions are taken.

In the interviewees' experience, Scrum led to better communication about problems and impediments among the team. Team members appeared to communicate not only more, "...but also more target-oriented. Interestingly enough, the results at this point are better." Significant parts of Scrum, which support the continuous improvement process, seem to be the retrospective meetings. This ritual kind of communication in the team appears to support the improvement process. Teams were able to talk about "what went wrong and what went right. In reality, it is mostly what went wrong." In one case, it was stated, that the team did a retrospective of the retrospective to see how well they improved their performance, whether measurements have been put into action and if not why they got off track.

It appears that teams must have the intention to change and improve, and Scrum only enables teams to do so more effectively. Sometimes suggestions came from the team's continuous improvement process that also contributes towards the continuous improvement of the company. One interviewee put it "plan, do, check, act, that is the premise that influences our daily actions (...) this conventional continuous improvement process, where we steadily want to get better. One the one hand better in the process and of course in the product too." In more detail, this means that plans (in the case of Scrum, Sprints are planned) are drafted to see what the task is about. Then the doing follows. Afterwards follows the check, which leads to act, where changes and improvements are done. Through its short work cycles and rituals Scrum leads teams to go through a PDCA-Cycle much more often than other methods. Hence this supports the continuous improvement process. It was also highlighted that the Scrum Master could guide the team towards improvement. 
From the interviews, it appears to be likely that Scrum supports the sharing of knowledge and experience. It probably is not the only trigger but intensifies the sharing. For example, the daily meetings enabled teams to share their experience. These meetings provided a platform for giving an impulse on an issue, which was then discussed in further detail afterwards. Scrum seems to provide a framework, which supports sharing of knowledge and experience, although it has been highlighted, that one should also utilise other methods.

As Scrum plans iteratively, team members are enabled to work on various small tasks, and can take over tasks that they normally would not have been able to. This can also be counterproductive when team members only do the tasks they are familiar with and walk away from challenging tasks. Sharing of knowledge and experience seems to be supported by Scrum even though it appears to depend on the team members. It should be valued and lived by teams as said here: "lack of knowledge is not bad here, only the ignorance not to ask questions"

Scrum seems to support high-involvement innovation, as every team member is deeply integrated into the process and is enabled to contribute towards innovation. Especially the constant exchange among the team appears to help here. What also seems to be beneficial overall here, is that in 3 out of 4 cases the interviewee's teams were multidisciplinary. On the one hand, thus not every team member could do every task, but the heterogeneity had a positive impact on working with customers and getting creative results. This is a factor that cannot be traced back to Scrum but might have a positive impact on Workplace Innovation.

\section{Workplace Partnership}

Concerning the impact of Scrum on the dialogue about the company, and being involved in change, the interviews showed mixed results. One interviewee attributed the fact that he felt well informed on a strategic level of the company to the size and structure of the company, and not to Scrum. Others though stated, that working with Scrum had a major impact on the whole company. In one example, the interviewee explained that through Scrum suggestions for the whole company were made. In this case, after having used Scrum in software development, it was rolled out in other areas of the company. The impulse for doing so came from the first Scrum Team.

In one example, candidates for a position in a Scrum team were also recruited and chosen by the Scrum Team itself: "We as a team want to present us in a job interview. But also get to know the candidate better". Although this is not an aspect of the Scrum framework itself, it might be a result of how the team has gained empowerment and self-manages through Scrum, and hence expanded its scope of action inside the company.

The aspect of integrating tacit and strategic knowledge is mostly covered in the above category of shared knowledge and experience, due to the interdependence of its aspects. Scrum has no impact on representative presentation.

Synergy Effects

Scrum appears to support an enabling culture well. It is necessary that the upper management is willing to understand agile methods and to implement them intransigently into the organisation. If an organisations' management is unwilling to do so or is afraid of the 
consequences of using agile methods, then "agile life will be stopped", or it will become difficult for an organisation to get there.

Interestingly none of the interviewees talked about team members who disapproved of the new way work is done. Scrum seemed to have improved team culture and may as well improve company culture. If Scrum is embedded in a bigger organisational structure, which allows failure, values respect and shows, it apparently works well.

If employees had bad experiences, such as "broken organisations (...) where people unlearnt to have their own standards (...) and they want again and again be told what to do", Scrum is less likely to be beneficial. Another aspect that was quoted is that of employee happiness. Scrum apparently has improved the happiness about work in the team, as stated by one interviewee. As happiness is a complex concept, this factor will not be investigated any further here.

The interviewees were at odds when it comes to the question, whether Scrum leads to more customer focus. This may be the case, if "(..) you get feedback which then flows into the planning for the next iteration. This is a much quicker exchange that in common projects. But you have to use it." The Product Owner seems to play a major role here. The interviews suggested that certain employees just tend to think more customer-oriented than others. What Scrum can contribute towards customer orientation is that it enables regular feedback opportunities as the customer can easily participate in the review meetings. As after each Sprint increments are delivered, the customer can give feedback on each of the increments, and has no longer to wait for months to see the whole outcome. Hence more interaction is possible when customers ask questions like: "Why did you do it like this? Like this or like that would be way better! This gives impulses and stimulation and helps the developers to comprehend how the customers think". In conclusion Scrum provides an opportunity for more customer focus, but the teams need to utilise it actively.

None of the interviewees saw that Scrum supported entrepreneurial behaviour among the team members. If employees think like an entrepreneur, this was perceived as given and was already in place before or was influenced by the size and structure of the company.

Furthermore, it seems to be the case that Scrum does not lead directly to more employee engagement. In the respective cases Scrum, led to a state where more work was done in the same amount of time with the previous methods. But this was characterised to be a secondary effect.

\section{Other factors that are indirectly linked to parts of the concept}

In the interviews, many other things came up, that either might contribute indirectly towards Workplace Innovation or seem otherwise relevant. The importance of an agile mindset is striking. Within most teams the agile mindset was already present, but Scrum further deepened the attitude. One of the main challenges when trying to use Scrum in organisations appears to be that management has to develop such an agile mindset. The idea of the agile principles, and how they impact work, is crucial to understand. In some cases, it turned out to be beneficial that the employees had no experience with Scrum, and in other situations having already worked in 
agile environments helped too. There seems to be no best practice, as the successful use and implementation of Scrum also depends on many other factors.

Another aspect, which is not part of the Fifth Element concept, but was often stated, is that communication improved significantly with the use of Scrum. People, who had not spoken with each other before, talked about projects and the processes. This was apparently mostly triggered by the regular meetings that became rituals. Again, the importance of the Scrum Master who can support the team was highlighted. One example is the daily meeting, as it allows the team members to get an insight into their co-workers work, and to share their problems and challenges. Being able to talk about impediments and obstacles may help to get those out of the way quicker.

Besides that, Scrum also had an impact on transparency, as it becomes clear how fast work gets done and what can probably be done in which amount of time. Teams were also able to see who does what, and if any team members misused their freedom to self-manage and let their team down.

It appears to be the case that employees with a high level of self-motivation profited from the implementation of Scrum. These employees were motivated by their own results, and as Scrum helped to deliver results in a short time span, it probably contributed to consistently high levels of motivation. But there were also teams that had no self-motivation, and hence Scrum could not support them.

What also appears to be important is the role and influence of senior managers of an organisation. As soon as managers were not willing to change, and if they perceived Scrum as something that is only for software development, the implementation of Scrum was unlikely to be successful. Then organisations fell back into old habits and processes and only used a "Zombie-Scrum (...) that has nothing to do with the mindset of a genuinely agile organisation." To implement Scrum successfully, management needs to let go, and potentially be supported and coached by Scrum experts. It is a change of mind from command and control, towards putting more trust into the teams, and the belief that they get the work done.

\section{Towards Agile Workplace Innovation: Putting empirical findings in context}

\section{Scrum as an Engine for Fifth Element Workplace Innovation}

Based on the empirical findings, Scrum can be interpreted to be an engine for Fifth Element Workplace Innovation. The interplay of Scrum and the Fifth Element Concept is illustrated and discussed below. Concerning the category of work organisation (1), Scrum may be able to support Workplace Innovation in many ways. Firstly, it may be, if implemented properly, a method to empower employees. Scrum can also be a management system that allows the employee to achieve his or her goals in their own way, which is a major aspect in Workplace Innovation. The empirical findings demonstrate the enabling role Scrum plays, as the approach itself will not lead to self-managing teams and teams themselves are rarely self-managing. "Employees taking the initiative and being able to work without supervision are valued, as it enables the workforce to make decisions based on their practical experience (...)" (Totterdill 
2015, p.65). Scrum enables to do that as teams self-manage and improve their teamwork. As highlighted before, teamwork is one of the key concepts in the new organisation of workplaces (Totterdill 2015, p.65) and Scrum supports it well. Based on this study, there is no evidence that Scrum supports the integration of technology.

On the aspect of structures and systems (2), one can conclude that Scrum may not be clearly attributed with reducing organisational walls and ceilings. In the cases where interviewees described their organisations as barrier-free, this had already been a precondition. If Scrum was implemented properly, employee initiative rose, but not automatically. Employee initiative is supported by the fact that teams self-organise, and have a better overview. Scrum does not inevitably lead to equality, but it enables transparency mainly through the improved communication. In general, Scrum seems to support building and maintaining trust, by allowing transparency about the work. The aspect of transparency is not part of "The Fifth Element Concept" of Workplace Innovation, but it is evident that it plays a major role in supporting it in general.

Scrum also supports the aspect of reflection and innovation (3) in many ways. Firstly, the retrospective meetings support continuous improvement and lead to better communication about problems and impediments among the team. The short work cycle makes teams go through a PDCA-Cycle more often, and hence gives more opportunities for reflection and improvement. Scrum seems to support high-involvement innovation, as every team member is deeply integrated into the process and is enabled to contribute. High involvement practices, such as decentralised decision making and co-operation, can lead to valuable results for organisations and the workforce (Ramstad 2014, p.25) and Scrum enables that, as teams decide on how to achieve their goals. It can be concluded, that Scrum provides a framework, which supports sharing of knowledge and experience. For example, retrospective meetings enable to share experience and knowledge, but other methods should also be utilised. 


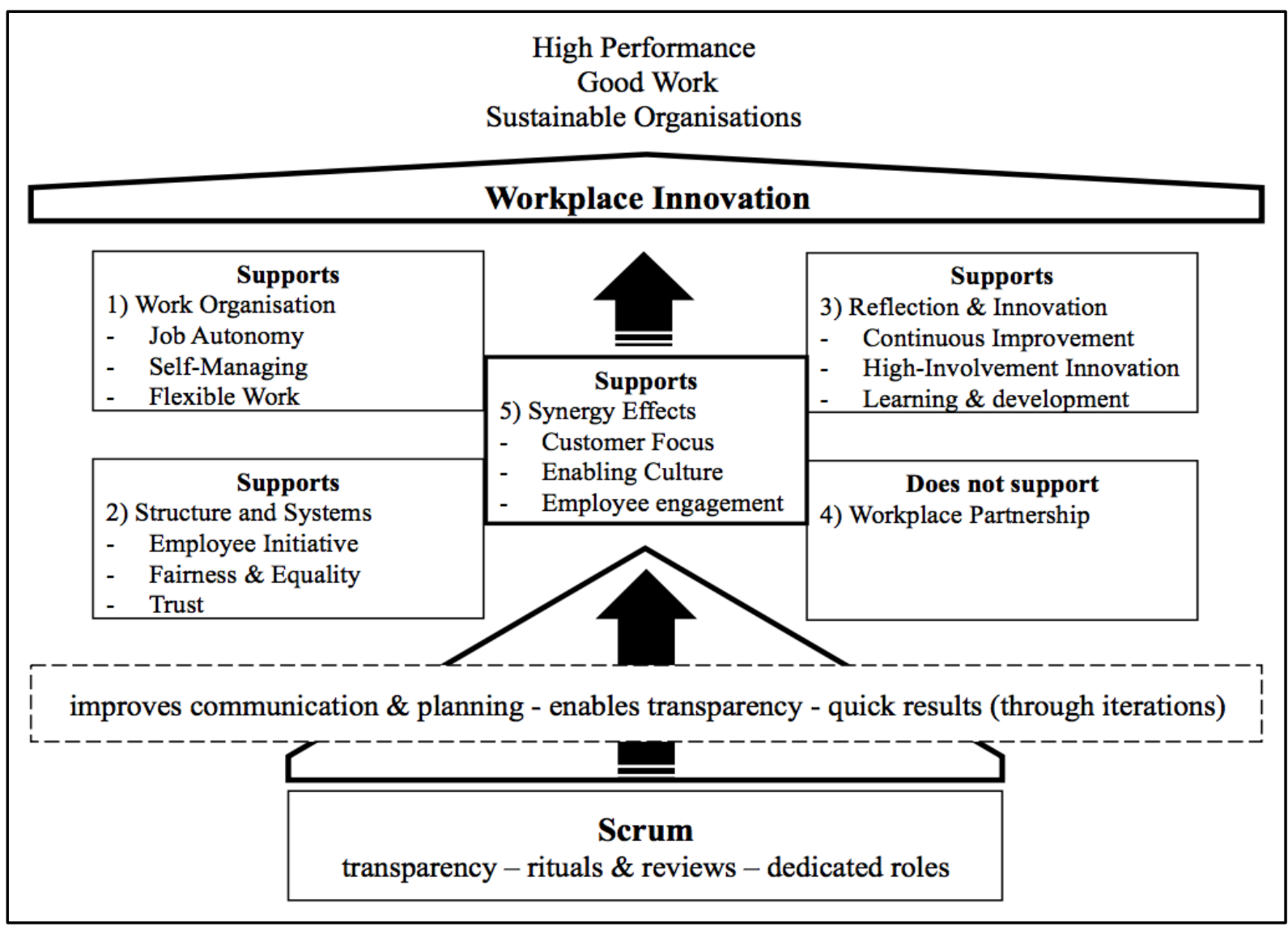

Figure 2:: Scrum and the Fifth Element Concept Summary of Results (adapted from Totterdill (2015))

From the conducted research one may conclude, that Scrum has no significant influence on the fourth aspect of workplace partnership (4), as none of the interviewees stated so. Scrum has had no impact on dialogue and representative presentation. Further research would be needed to confirm it, but it appears to be a result of Scrum, that teams expand their scope of action inside an organisation if they enjoy empowerment and self-manage over a longer period. For example, it was stated that a Scrum team took over the recruiting process. The aspect of integrating tacit and strategic knowledge is mostly covered in the above category of shared knowledge and experience, due to the interdependence of its aspects.

The coming together of the above aspects has synergy effects (5), which are partially supported by Scrum. It contributes towards customer focus through its regular feedback opportunities as the customer can easily participate in the review meetings and give feedback. As "employees often know best what their customers want" (Totterdill 2015, p.65), Scrum provides an opportunity for more customer focus, but it is up to the teams to make use of it. The factor of employee engagement has already been covered, with the aspect of employee initiative. Scrum appears to support an enabling culture well if it is embedded in a bigger organisational structure, which allows failure, values respect and shows appreciation. Since resilience is a broad concept, no conclusion can be made here on the impact of Scrum. As has been stated above, Scrum has no apparent influence on employee relations. Scrum also was not related to supporting entrepreneurial behaviour. 
Other positive outcomes of Scrum that were stated and that potentially support Workplace Innovation are improved communication, improvements in planning and the fact that working iteratively gets quick results. Besides that, Scrum supports transparency, which might be one of the key success factors as "far too often in a company it is not really clear what everyone is working on, or how each person's daily activity advances the goals of the company" (Sutherland 2014, p.153).

In conclusion, Scrum can support Workplace Innovation on many levels, mainly on the aspects of Work Organisation (1), Structure and Systems (2) and Reflection and Innovation (3). It does not explicitly support Workplace Partnership (4) and all Synergy Effects (5), but it leads to other positive outcomes, which may, in turn, support Workplace Innovation. Scrum cannot be a magic bullet, but may be a useful framework, along with other (agile) methods, to support Workplace Innovation.

\section{Implications and Constraints}

It should be noted, that academic literature on Scrum is still rare, and Workplace Innovation is still a rather new concept. The qualitative research presented here provides only finite insights, as the number of interviews was small.

For the perspective of Scrum, it would have been interesting to hear the insights of Product Owners and members of the development team. Furthermore, there was no expert on Workplace Innovation available in the respective time frame as an interview partner. Hence the results are based on insights from Scrum practitioners only.

Most importantly it should be noted, that the net effect of Scrum cannot be isolated, as there regularly are other factors which also contribute to Workplace Innovation. It may well be the case that certain environments already were on a good path towards Workplace Innovation, and that this was one of the reasons why that organisation started using Scrum. In general, it was difficult to divide between what changed with the implementation of Scrum, and what had already been given in the particular cases.

Having in mind the vast body of research on each of the elements in the concept of Workplace Innovation, the contribution of the work presented here remains rather limited. But there is a lack of research on Workplace Innovation as a general concept. The goal was to investigate the whole concept, and not its aspects, because the concept of Workplace Innovation is about the coming together of the elements. This work still can provide a starting point for further in-depth research, and has shown that Scrum and Workplace Innovation are subjects that are worth further investigation.

\section{Proposed follow-up research questions and outlook on further work}

Future research may look deeper into the individual elements of the Fifth Element framework, to seek a better understanding of the contribution of agile methods to workplace innovation. This could entail specific reviews of the dedicated roles under Scrum, like the Scrum Master, the Product Owner and the development team. A complementary approach can be to track the 
co-evolution of agile methods and Workplace Innovation in different industries and functional areas, especially outside software engineering, like for example agile R\&D (Rodriguez et.al. 2012), agile purchasing (Diekmann 2017) or agile manufacturing (Leite and Braz 2016). It will be instructive to connect to the related fields like New Work (Laloux 2014 and Appelo, 2011) or democratic approaches to corporate organisation (Sattelberger et. al. 2015).

\section{About the Authors}

Thomas Papke

Consultant at Detecon International GmbH, Sternengasse 14-16, 50676 Köln, Germany

Tel. +49 15731702308 Email: tpapke@karlshochschule.de

After graduation from Karlshochschule, he gained his MSc from UCD Michael Smurfit Business School in Dublin, Ireland. He is currently involved in projects in digitisation and the implementation of agile methodologies in organizations. His research interests are in the areas of innovation, corporate culture and change management.

Dirk Nicolas Wagner,

Professor of Strategic Management, Dean of Faculty of Business Economics and Management, Karlshochschule International University, Karlstrasse 36-38, 76135 Karlsruhe, Germany.

Tel. +49 721 48095-508. Email: dwagner@karlshochschule.de

Prior to joining Karlshochschule, he served in senior management positions and as a board member in the Technical Services Industry in Europe. His professional background includes major projects in oil \& gas, power and rail infrastructure. His research interests are in the areas of innovation, management for man and machine and project management.

\section{References}

Appelo J., 2011. Management 3.0. Leading Agile Developers, Developing Agile Leaders. Addison-Wesley Professional.

Brandes U., Gemmer P., Kuschek H., Schültken,L., 2014. Management Y: Agile, Scrum, Design- Thinking \& Co.: so gelingt der Wandel zur attraktiven und zukunftsfähigen Organisation. Campus- Verlag, Frankfurt am Main.

Brinkmann S., 2013. Qualitative interviewing, Series in understanding measurement. Oxford University Press, Oxford.

Conforto E.C., Salum F., Amaral D.C., da Silva S.L., de Almeida L.F.M., 2014. "Can Agile Project Management Be Adopted by Industries Other than Software Development? "Project Management Journal 45, 21-34. 
Denning S., 2013. "Why Agile can be a game changer for managing continuous innovation in many industries". Strategy \& Leadership 41, 5-11.

Dieckmann A. K. (2017). „Agilität im Einkauf-Eine Methoden-Architektur zur Konfiguration und Adaption einer agilen Belegschaft im Einkauf". In Personalentwicklung in der Beschaffung (pp. 51-74). Springer Berlin Heidelberg.

Ennals R., 2014. "Workplace Innovation", in: Responsible Management. Springer Berlin Heidelberg, Berlin, Heidelberg, pp. 1311-129.

Gkiontsi D., \& Karanika-Murray M. (2016). "Dealing with economic and demographic challenges: Workplace innovation practices as a timely and effective response to older workers' needs". European Journal of Workplace Innovation, 2(1), pp.25-42.

Goll J., Hommel D., 2015. Mit Scrum zum gewünschten System. Springer Fachmedien, Wiesbaden.

it-agile.de, 2015. The Scrum Cycle, it-agile.de. http://www.it-agile.de/wissen/methoden/scrum/ Kalmi P., Kauhanen A., 2008. "Workplace Innovations and Employee Outcomes: Evidence from Finland”. Industrial Relations 47, 430-459.

Kent B., Beedle M., van Bennekum A., Cockburn, A., Cunnigham W., Fowler M., Grenning J., Highsmith J., Hunt A., Jeffries R., Kern J., Marick B., Martin R.C., Mellor S., Schwaber K., Sutherland J., Thomas D., 2001. Manifesto for Agile Software Development.

Kuckartz U., 2010. "Einführung in die computergestützte Analyse qualitativer Daten ", 3., aktualisierte Aufl. ed, Lehrbuch. VS, Verl. für Sozialwiss, Wiesbaden.

Kuckartz U. (Ed.), 2008. "Qualitative Evaluation: der Einstieg in die Praxis“, 2., aktualisierte Aufl. ed. Lehrbuch VS, Verl. für Sozialwiss, Wiesbaden.

Laloux F. 2014. Reinventing Organizations: A Guide to Creating Organizations Inspired by the Next Stage in Human Consciousness. Nelson Parker

Leite M., Braz V., 2016. “Agile manufacturing practices for new product development: industrial case studies." Journal of Manufacturing Technology Management. 2016, Vol. 27 Issue 4, p560-576. 17p.

Mayring P., 2010. "Qualitative Inhaltsanalyse: Grundlagen und Techniken, 11“., aktualisierte und überarb. Aufl. ed, Beltz Pädagogik. Beltz, Weinheim.

Moe N.B., Dingsøyr T., Dybå T., 2010. “A teamwork model for understanding an agile team: A case study of a Scrum project”. Information and Software Technology 52, 480-491.

Pot F., 2011. "Workplace innovation for better jobs and performance". International Journal of Productivity and Performance Management 60, 404-415. 
Pot F.D., Koningsveld E.A., 2009. "Quality of working life and organizational performance two sides of the same coin? "Scandinavian Journal of Work, Environment \& Health 35, 421428.

Ramstad E., 2014. "Can High-involvement Innovation Practices improve Productivity and the Quality of Working-life simultaneously? Management and Employee Views on Comparison". Nordic journal of working life studies 4, 25-45.

Randall R.M., 2014. "Agile at IBM: software developers teach a new dance step to management." Strategy \& Leadership 42, 26-29.

Rigby D., Sutherland J., Takeuchi H., 2016. "Embracing Agile". Harvard Business Review. May2016, Vol. 94 Issue 5, p40-50.

Rubin K.S., 2012. Essential Scrum: a practical guide to the most popular agile process. Addison- Wesley, Upper Saddle River, NJ.

Rodriguez R., Minguella J., Fenollosa F., Ventayol B., Santos A., 2012. "Experiences in Agile R\&D Project Management for New Product Design and Development in the Automotive Industry". A: International Research / Expert Conference. "TMT 2012 Proceedings". Dubai, p. 223-226.

Sattelberger T., Welpe I., Boes A., 2015. Das demokratische Unternehmen: Neue Arbeits- und Führungskulturen im Zeitalter digitaler Wirtschaft. Haufe Lexware

Schwaber K., Sutherland J., 2013. The Scrum GuideTM.

http://www.scrumguides.org/docs/scrumguide/v1

Sutherland J.V., 2014. Scrum: a revolutionary approach to building teams, beating deadlines, and boosting productivity, Random House, London

Takeuchi H., Nonaka I., 1986. "The new product development game." Harvard Business Review 64, 137-146.

Tidd J., Bessant J.R., 2013. Managing innovation: integrating technological, market and organizational change, Fifth edition. ed. John Wiley \& Sons, Chichester, West Sussex, United Kingdom.

Totterdill P., 2015. "Closing the Gap: The Fifth Element and Workplace Innovation”. EJWI 1, $55-74$.

Williams L., 2012. "What agile teams think of agile principles." Communications of the ACM 55,71 . 